\title{
Solar Chimney Model Parameters to Enhance Cooling PV Panel Performance
}

\author{
Mohammed Sh-eldin ${ }^{1}$, K. Sopian ${ }^{1}$, Fatah O. Alghoul ${ }^{1}$, Abdelnasser Abouhnik ${ }^{2}$ \& Ae. Muftah M. ${ }^{3}$ \\ ${ }^{1}$ Solar Energy Research Institute, Faculty of Eng., Universiti Kebangsaan Malaysia, Selangor, Malaysia \\ ${ }^{2}$ School of Science \& Engineering, Manchester Metropolitan University, Manchester, UK \\ ${ }^{3}$ Faculty of Industrial Science and Technology, University Malaysia Pahang, Kuantan, Malaysia \\ Correspondence: Mohammed Sh-eldin, Solar Energy Research Institute, Faculty of Eng., Universiti Kebangsaan \\ Malaysia, Selangor, Malaysia. E-mail: xiaoyao6554@gmail.com
}

Received: November 11, 2012

Accepted: January 14, 2013 Online Published: January 21, 2013

doi:10.5539/mas.v7n2p24

URL: http://dx.doi.org/10.5539/mas.v7n2p24

\begin{abstract}
The concept of using the Solar Chimney plays an important role in a wide range of topics to improve cooling system efficiency such as drying process, and single and multi-story buildings ventilation against temperature rising. In this paper, study the effective solar cooling chimney parameter model to enhance the performance of photovoltaic (PV) cooling system. First, a brief description of theoretical performance predictions of the solar cooling chimney also discusses the effect of the ambient wind velocity on the photovoltaic panel. Second, analysis air velocities at different points in solar cooling chimney are predicted and the temperature drop also estimated to predicted air velocities in the duct. Finally, from simulation result it was found for chimney height range $0.3 \mathrm{~m}-3 \mathrm{~m}$ and at $60{ }^{\circ} \mathrm{C}$, the air velocity increase from 0.6 to $1.78 \mathrm{~m} / \mathrm{s}$ and Pressure difference between inlet and outlet increase from 0.5 to $5.3 \mathrm{KPa}$, which improve the PV panel voltage $8 \%$.
\end{abstract}

Keywords: air cooling, natural convection, solar cell cooling, solar cooling chimney

\section{Introduction}

In last three decades solar chimneys (SC) are applied in different fields such as ventilation, drying process, or production of electricity systems. Solar chimney is passive elements and one of the most promising a natural power generator using the stack effect to induce buoyancy-driven airflow. Schlaich (1995) indicated solar chimney was primarily used for power generation. It utilizes solar radiation to increase the air temperature inside the SC channel and the resulting generates the buoyant flow through the channel. Photovoltaic panels have negative temperature coefficient due to which its open circuit voltage decreases by certain $\mathrm{V} /{ }^{\circ} \mathrm{C}$ of rise in the panel temperature and it convert's small amount of the incident solar radiations to electricity while some amount of solar radiation is converted to heat.

Many researchers introduce many theoretical and experimental studies and focused mainly on SC structure optimization such as minimize installation cost and maximize power output. Various methods of cooling a solar cell have been previously suggested in the literature (Royne et al., 2005; Anderson et al., 2008; Kermani et al., 2009; Moshfegh \& Sandberg, 1998). Most of the methods that are used for cooling of PV panel involve an active medium which requires auxiliary power. Having an active cooling system for photovoltaic cell will make it costly and complicated have the ongoing maintenance cost. Air flow due to buoyancy and heat transfer in a vertical channel heated with simulated heat source has been investigated numerically and experimentally (Akbarzadeh et al., 2009). Moshfegh and Sandberg (1998) has shown that 30\% of heat flux is transfer to the unheated wall of the duct from the PV panel by radiation and then this heat is transferred to the air in the duct, this helps to increase the air temperature and in turn the air velocity. Brinkworth (2000) has presented a routine procedure to estimate the air flow under an inclined roof top PV panel and have mention the importance of radiation heat transfer in improving the air flow in the duct or the air gap between the PV panel and roof. Some work using commercial PV panels and outdoor experiments has been first carried out by (Tonui \& Tripanagnostopoulos, 2008) and they focused on investigating the thermal performance of PV air collector.

This paper described the possibility of integrating the chimney effect to cool the photovoltaic cell. A mathematical model was developed and analytical performances prediction, such as the output and the power 
delivered by a solar chimney power plant, according to geometrical parameters, such as the height, length, cavity width and the solar radiation.

\section{Description Solar Cooling Chimney (SCC)}

From Figure 1, the solar radiation is incident on the transparent bottom surface of the solar chimney. These solar radiations are absorbed by the air that is under the solar chimney which eventually gets warmed up and its density decreases. The warm air will try to rise up sue to the buoyancy force and escape through the chimney. Tall chimney will provide a pressure difference between the bottom and the top which will further assist in the draft of the air. This velocity of air is utilized to drive the turbine inside the chimney that will generate the electricity.

This design consists of a dedicated absorber section in addition to the design suggested by Tonui and Tripanagnostopoulos (2008) such that it will help to enhance the natural draft of air which can be utilized for cooling of PV panels. The velocity of air rising up in the chimney is directly proportional to the energy absorbed by the air.

SCC is decided into two main parts: top part, and the middle part as shown in Figure 1.

Top part of the SCC consists of the vertical extension to the middle part. Top part will act like a chimney in this setup to enhance the natural draft created by the warm rising air.

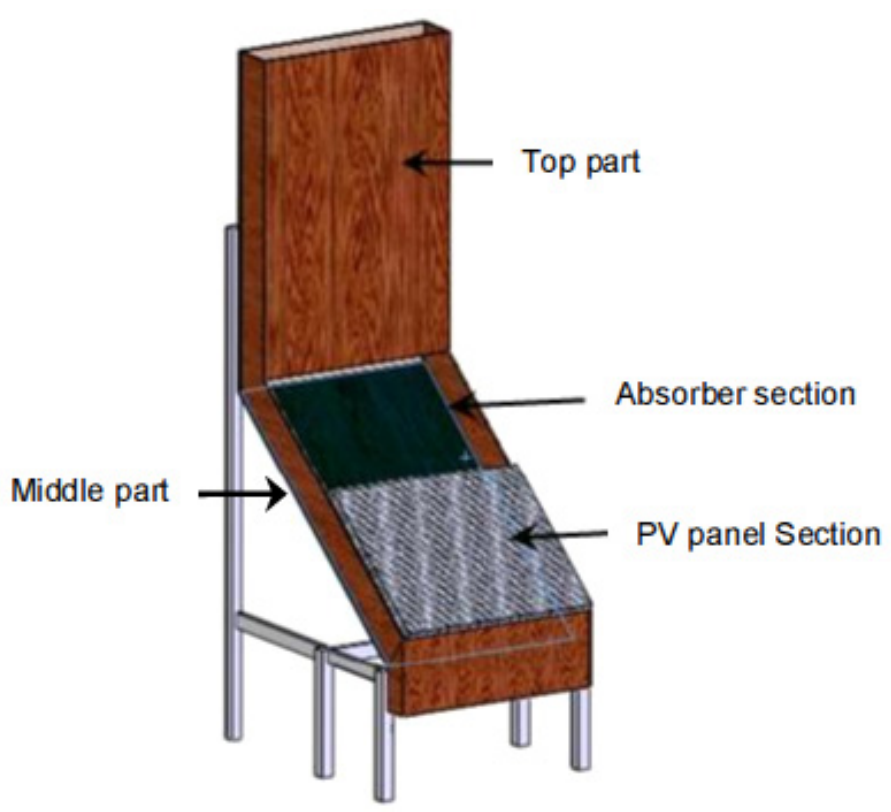

Figure 1. Solar cooling chimney

The middle part of Solar cooling chimney consists PV panel section and absorber section and designed such that its length is twice as long as the PV panel length. As shown in Figure 2 PV panel is mounted on the lower half of middle part while a transparent acrylic sheet is placed on the top half of the middle part. Middle part of solar cooling chimney is mounted at an inclination angle equal to local latitude to make sure that the PV panel and absorber section receives maximum solar radiation throughout the year. 


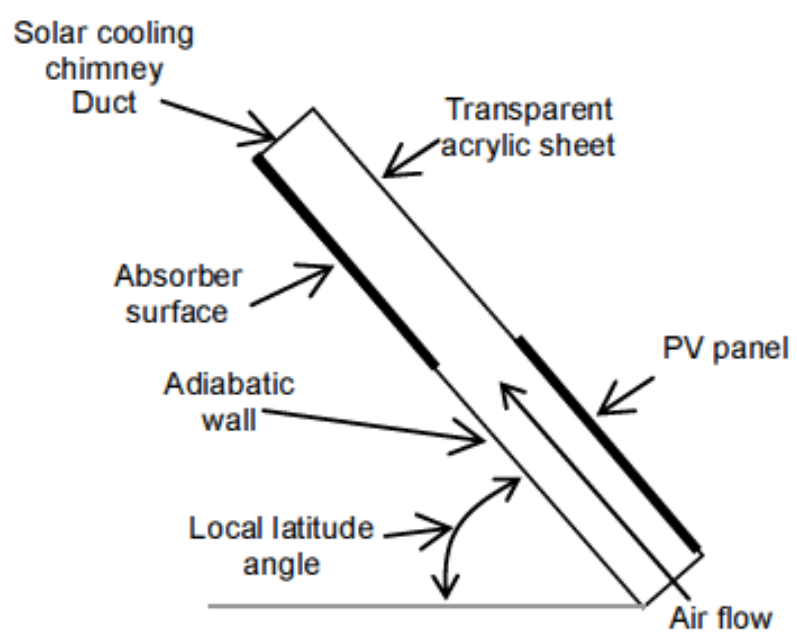

Figure 2. Middle section of solar cooling chimney

Most of the incident solar radiations will pass through the transparent acrylic sheet depending on its emissivity and reflectivity and fall on absorber surface. Absorber surface is painted black to maximize the amount of energy absorbed. As a result the temperature of the absorber surface will increase. High temperature absorber surface will transfer the heat to the air coming from the PV panel section.

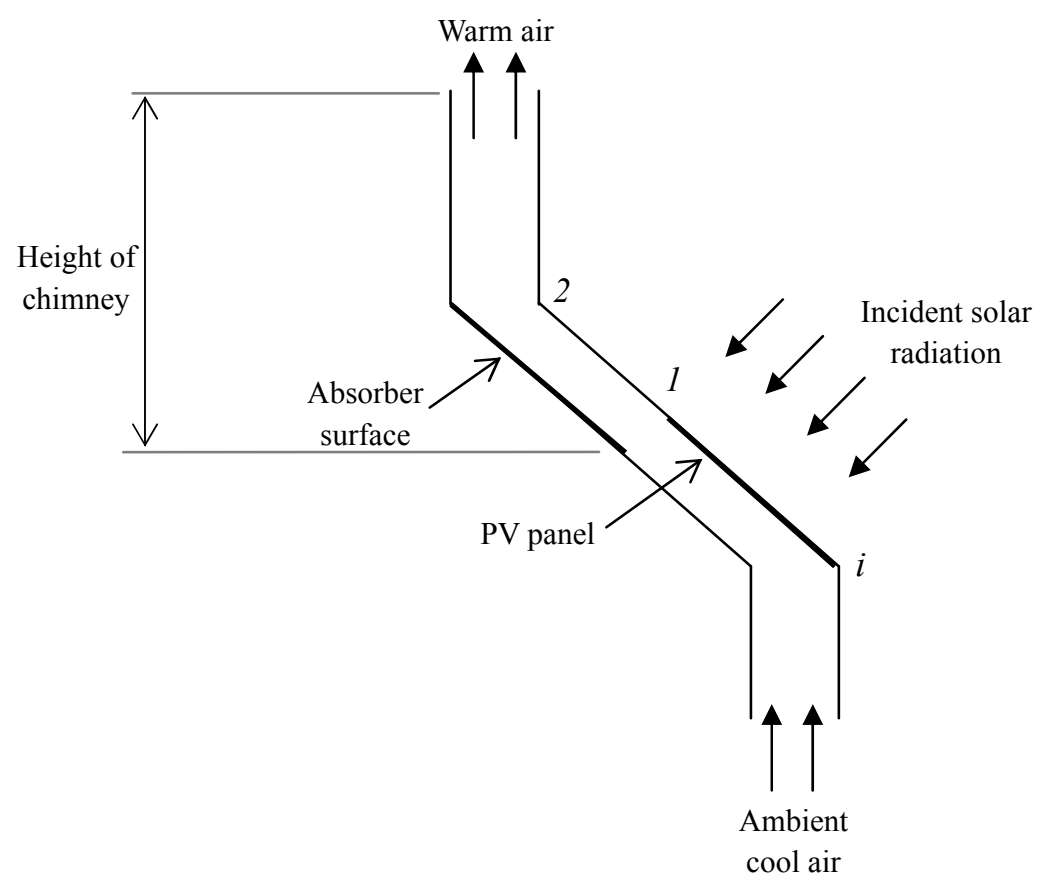

Figure 3. Solar cooling chimney dimension

Warm air with lesser density will rise upwards towards the top section. Height of the top part of SCC will assist the warm air to rise toward the top due to the static head difference. Air flow velocity will increase if we increase the height of chimney. The natural air draft in the duct induced due to the density difference between the air in the middle part and ambient air above the top part will create the suction to allow ambient air to enter from bottom of SCC as shown in Figure 3. Ambient cool air entering from the bottom of SCC will flow over the heated PV panel surface and reduce its temperature. 


\section{Model Theoretical Analysis}

The following section presents the theoretical analysis of the solar cooling chimney as shown in Figure 4. The governing equations are derived using combination of conservation of energy and conservation of mass and momentum across the duct of the Solar Cooling Chimney to predict the values air velocities at the outlet. Energy balance equations for two separate sections in the solar cooling chimney are presented further. Figure 4 shows the PV panel section in which the PV panel is mounted on the inclined duct of the solar cooling chimney.

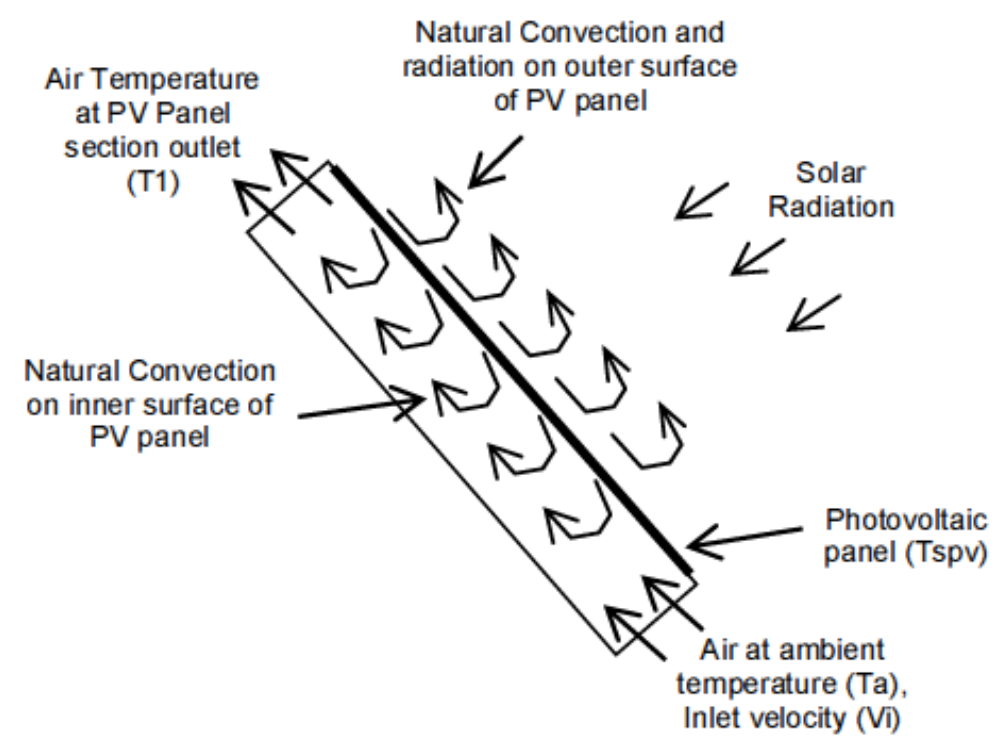

Figure 4. Heat transfer over the PV panel surface

\section{PV panel section (point $i$ to point 1 )}

Energy received by PV panel:

$$
E_{i n-p v}=I \times A_{p v} \times\left(1-\eta_{p v}\right) \times \tau_{p v}
$$

Heat is transferred from outer and inner surface of the PV panel. Heat is transferred from outer of the PV panel via natural convection and radiation. Heat is transferred from inner surface via forced convection and radiation.

$$
E_{l o s s-p v}=h_{n a t} A_{p v}\left(T_{s p v}-T_{a}\right)+h_{f o r} A_{p v}\left(T_{s p v}-T_{a}\right)+\varepsilon \sigma A_{p v}\left(T_{s p v}^{4}-T_{a}^{4}\right)
$$

Nusselt number equation for natural convection over inclined plate (Churchill \& Chu, 1975):

$$
N u=\left(0.825+\frac{0.387 R a^{1 / 6}}{\left[1+(0.492 / \mathrm{Pr})^{9 / 16}\right]^{8 / 27}}\right)^{2}
$$

Nusselt number equation for forced convection (Churchill and Ozoe, 1973):

$$
N u=\frac{0.3387 \operatorname{Pr}^{1 / 3} \operatorname{Re}^{1 / 2}}{\left[1+(0.0468 / \operatorname{Pr})^{2 / 3}\right]^{1 / 4}}
$$

The Reynolds number, Re is a function of the inlet velocity, $V_{i}$ which is unknown.

The surface temperature $T_{\mathrm{spv}}$ is found by equating Equation (1) and Equation (2):

$$
h_{n a t}\left(T_{s p v}-T_{a}\right)+h_{f o r}\left(T_{s p v}-T_{a}\right)+\varepsilon \sigma\left(T_{s p v}^{4}-T_{a}^{4}\right)=I \times\left(1-\eta_{p v}\right) \times \tau_{p v}
$$

Equation (5) is a non-linear equation.

The temperature of the air at outlet of the PV section $T_{1}$ can be determined using the log mean temperature difference between the ambient temperature and the PV surface temperature. 


$$
T_{1}=\frac{T_{s p v}-T_{a}}{\ln \left(\frac{T_{s p v}}{T_{a}}\right)}
$$

The density of moist inlet air is calculated by

$$
\rho_{i}=\rho_{d r y, i}+\rho_{v, i}
$$

where density of dry air and water vapor are both estimated by ideal gas law.

Here, the partial pressure of water vapor can be determined by

$$
P_{v, i}=\varphi_{i} P_{s a t, i}
$$

while the partial pressure of dry air be determined by

$$
P_{d r y, i}=P-P_{v, i}
$$

where $\Phi_{i}$ is the relative humidity of air at inlet of PV panel, $P_{\text {sat, } i}$ is the partial pressure of vapor for saturated air at that temperature, and $P$ is the absolute pressure.

Similar procedure is used to calculate density of air at outlet of PV panel, with

$$
\frac{P_{v, i}}{P_{v, 1}}=\frac{T_{i}}{T_{1}}
$$

In the duct, pressure difference will be created by the warmer air at the inlet and cooler air at the outlet. The natural draft pressure caused by the difference in outside and inside air density is given by

$$
\Delta P_{s}=\left(\rho_{i}-\rho_{1}\right) \times g \times H_{c}
$$

where $H_{c}$ is the height of chimney duct and $g$ is the gravitational acceleration $\left(9.81 \mathrm{~m} / \mathrm{s}^{2}\right)$.

The total pressure loss in a duct can be calculated by

$$
\Delta P_{\text {loss } P V}=\left(\frac{f L}{D_{h}} \times \frac{\rho_{\text {avg }} V_{1}^{2}}{2}\right)+\left(\frac{k \rho_{\text {avg }} V_{1}^{2}}{2}\right)
$$

By equating Equation(11) and Equation(12), we can determined the velocity, $V_{l}$ of the air.

$$
V_{1}=\sqrt{\frac{\left(\rho_{i}-\rho_{1}\right) \times g \times H_{c}}{\frac{\rho_{\text {avg }}}{2}\left(\frac{f L}{D_{h}}+k\right)}}
$$

\section{Absorber section (point 1 to point 2)}

Energy absorbed by absorber surface:

$$
E_{\text {in-abs }}=I \times A_{\text {abs }} \times \tau_{\text {trans }} \times \tau_{\text {abs }}
$$

Energy loss of the absorber:

$$
E_{\text {loss-abs }}=h_{\text {conv }} A_{a b s}\left(T_{s a}-T_{1}\right)+\varepsilon \sigma A_{a b s}\left(T_{s a}^{4}-T_{1}^{4}\right)
$$

$h_{\text {conv }}$ is calculated from Nusselt number for forced convection (Churchill \& Ozoe, 1973). 


$$
N u=\frac{0.3387 \operatorname{Pr}^{1 / 3} \operatorname{Re}^{1 / 2}}{\left[1+(0.0468 / \operatorname{Pr})^{2 / 3}\right]^{1 / 4}}
$$

Similar to the PV panel section, $\mathrm{T}_{\mathrm{sa}}$ can be found by equating Equation(14) and Equation(15).

The log mean temperature of the absorber section is

$$
T_{2}=\frac{T_{s a}-T_{1}}{\ln \left(\frac{T_{s a}}{T_{1}}\right)}
$$

Similar procedure is used to calculate the velocity of air, $V_{2}$ at this section.

$$
V_{2}=\sqrt{\frac{\left(\rho_{1}-\rho_{2}\right) \times g \times H_{c}}{\frac{\rho_{\text {avg }}}{2}\left(\frac{f L}{D_{h}}+k\right)}}
$$

Conservation of mass principle is used to calculate $V_{i}$. Mass balance across inlet (i) to outlet of absorber (2) is

$$
\begin{gathered}
\rho_{2} V_{2} A_{\text {duct }}=\rho_{i} V_{i} A_{\text {duct }} \\
V_{i}=\frac{\rho_{2} V_{2}}{\rho_{i}}
\end{gathered}
$$

The value of $V_{i}$ from Equation(20) is now used in the calculation of Equation(4) in the PV section where heat transfer coefficient of forces convection can now be calculated. Iteration is continues until $V_{i}$ is converged. However, since the $h_{c}$ is rather small (comparative with $h_{n}$ ), so only one or two iteration is required (expected result).

\section{Results and Discussion}

In this section the theoretical solar cooling chimney model analysis as shown in Figures 5 to 7 . In Figure 5, the total static pressure difference generated between the inlet and outlet of solar cooling chimney is plotted against height of chimney. It can be prominently seen that the static pressure difference across the inlet and outlet of the solar cooling chimney goes on increasing as the height of chimney increases. Temperature of outlet air has a similar effect on the static pressure of air across solar cooling chimney. This static pressure difference between the inlet and outlet of the solar cooling chimney does not behave like velocity in the Figure 7 since the major losses due to friction and minor losses due to the shape of the chimney are not includes in this static pressure.

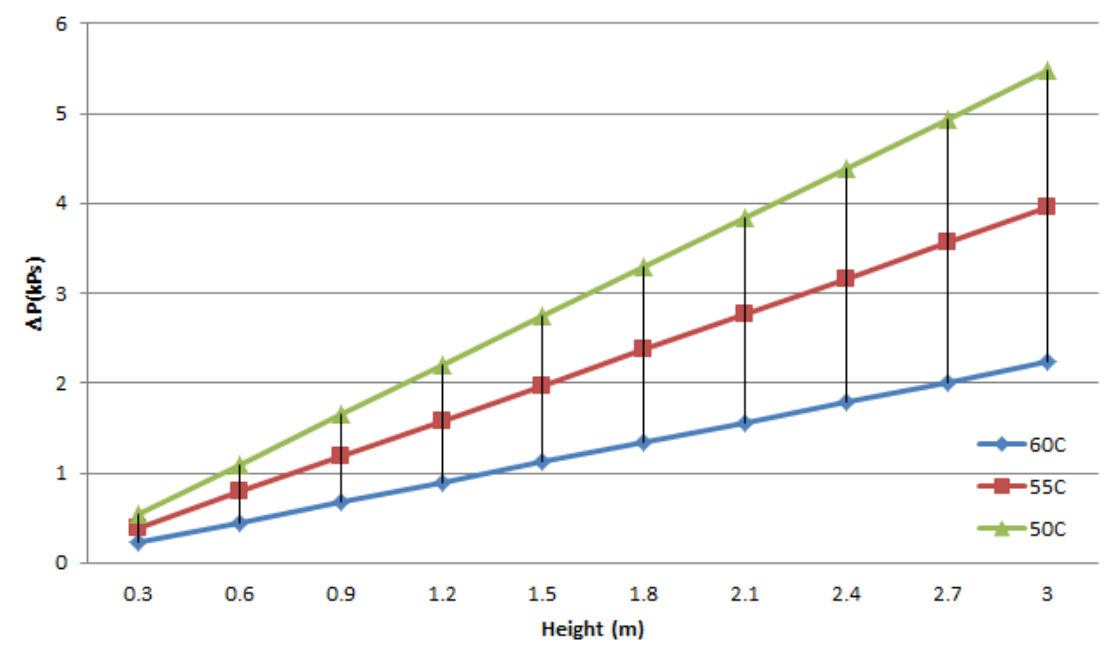

Figure 5. Static pressure difference between inlet and outlet of solar cooling chimney with respect to height

Figure 6 provides us information about the outlet air velocities that could be achieved in a chimney with its height starting from $0.1 \mathrm{~m}$ and increasing till $1 \mathrm{~m}$ tall. The air velocities for outlet air temperature of between 323 
$\mathrm{K}\left(50{ }^{\circ} \mathrm{C}\right)$ to $333 \mathrm{~K}\left(60^{\circ} \mathrm{C}\right)$ are presented. It is observed as expected that the air velocity due to natural draft will go on increasing as the solar cooling chimney height increases. Similar to the height of solar cooling chimney, temperature of outlet air will have a similar effect on the velocity if outlet air. As the temperature of outlet air will increase the velocity of air will rise. It is interesting to see that these curves have a logarithmic trend. It can be predicted that the velocity rise of air will be stagnated after certain increase of height of solar cooling chimney for different outlet air temperatures. The optimum solar cooling chimney height could be determined if this curve is extended for higher chimney heights.

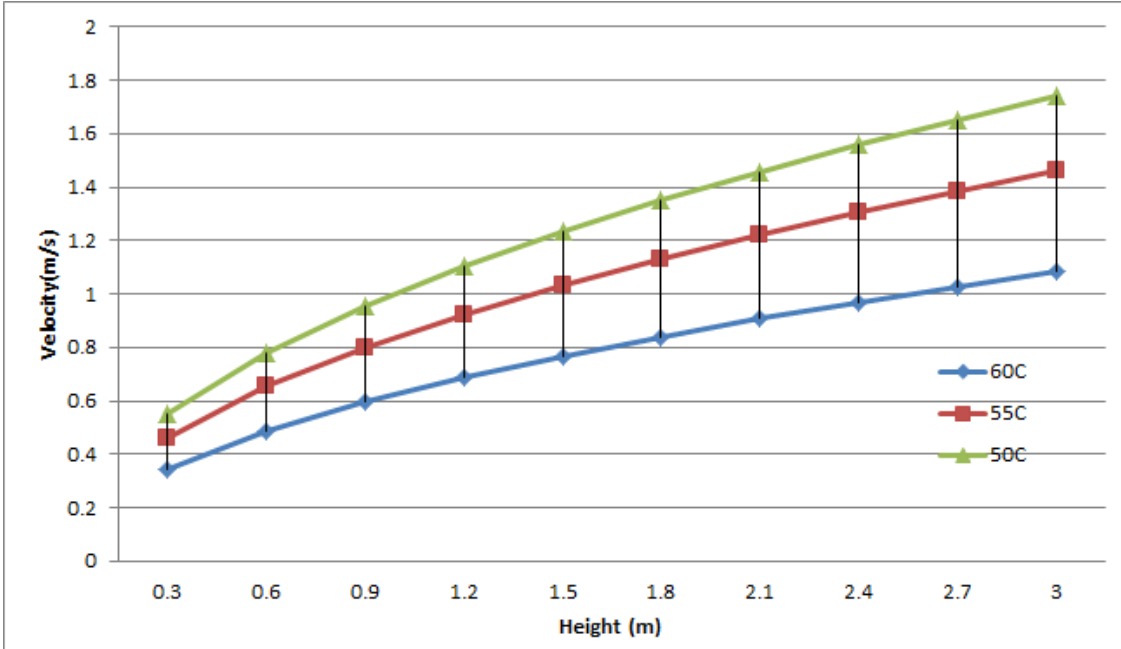

Figure 6. Air velocity in the solar cooling chimney with respect to the height of solar cooling chimney

Figure 7 illustrates the predicted surface temperature of photovoltaic panel attached with solar cooling chimney. These temperature values are determined using the velocity of air predicted in the earlier section. The natural draft in the duct will pull the ambient air from the bottom of the duct. Ambient air in this case is considered to be at $20{ }^{\circ} \mathrm{C}$, which will flow over the back heated surface of the photovoltaic panel with the predicted velocity. This will cause the convection heat transfer from the photovoltaic panel. Nusselt number correlation for forced convection with either laminar or turbulent flow (Whitaker, 1972) is used to determine the convection heat transfer coefficient. Further the convection heat transfer coefficient along with Newton's law of cooling is used to predict the temperature of the photovoltaic panel. The temperature of the photovoltaic panel goes on reducing as the chimney height increases. This can be justified from the earlier graph in Figure 7, since the velocity of air increases it will increase the convection heat transfer coefficient reducing the temperature of the photovoltaic panel.

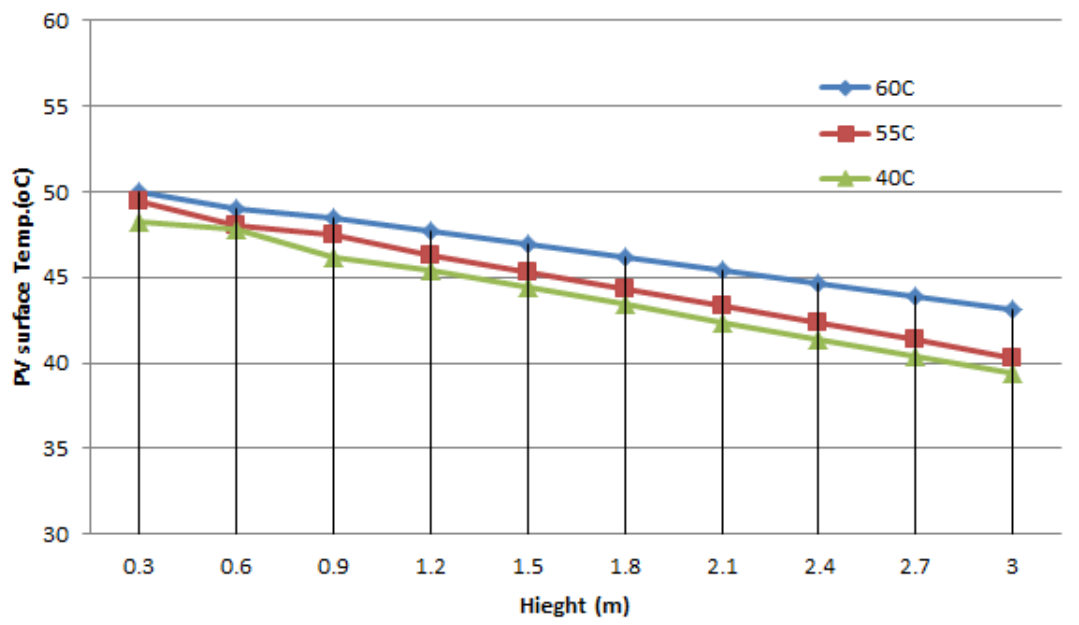

Figure 7. Predicted PV panel surface temperature with respect to change in height of solar cooling chimney 
Figure 8 illustrates the improved voltage from the PV panel due to reduced surface temperature. As the solar cooling chimney height goes on increasing the output voltage from the PV panel will increase. In addition improving voltage will follow the outlet air velocity trend.

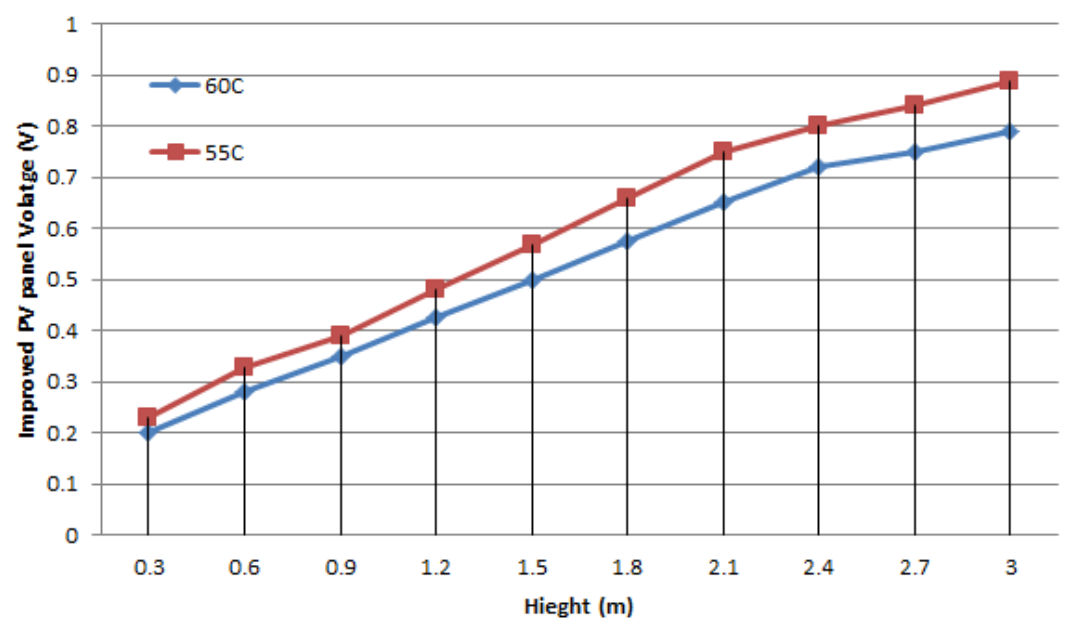

Figure 8. Effect of negative temperature coefficient on open circuit voltage of the PV panel

From above operation conditions, there is an optimum working temperature mentioned to achieve the said open circuit voltage. As the operating temperature of the PV panel goes on increasing the open circuit voltage will drop. This will reduce the efficiency of the PV panel as well.

\section{Conclusion}

The natural air draft that is achieved by buoyancy effects in a chimney can be used as a passive cooling medium for PV panels. Simple modification in the design of the system and including the additional absorber section can help to improve the induced natural draft of air and as a result helps improve the performance of the PV panel. Simple and preliminary analysis shows that by coupling the solar cooling chimney with a PV panel we can achieve considerable cooling of the PV panel and improve the efficiency of the PV panel. Taller chimneys can increase the velocity of air and further reduce the working temperature of PV panel to make it more efficient. Although taller chimneys will increase the overall cost of the system and reduce the simplicity in design. Taller chimney will also have a shading effect in case of PV panels are placed close to each other. Solar cooling chimney height should be optimized for the cost effectiveness and shading effect. Another way to improve the cooling / heat removal would be by increasing the surface area of the absorber section. Further investigation is required to accurately measure velocity of induced natural draft.

\section{References}

Akbarzadeh, A., Johnson, P., \& Singh, R. (2009). Examining potential benefits of combining a chimney with a salinity gradient solar pond for production of power in salt affected areas. Solar Energy, 83, 1345-1359. http://dx.doi.org/10.1016/j.solener.2009.02.010

Anderson, W. G., Dussinger, P. M., Sarraf, D. B., \& Tamanna, S. (2008). Heat pipe cooling of concentrating photovoltaic cells. In: Photovoltaic Specialists Conference, 2008. PVSC '08. 33rd IEEE. pp. 1-6. http://dx.doi.org/10.1109/PVSC.2008.4922577

Brinkworth, B. J. (2000). Estimation of flow and heat transfer for the design of PV cooling ducts. SolarEnergy, 69, 413-420. http://dx.doi.org/10.1016/S0038-092X(00)00082-7

Cengel, Y. A., Cimbala, J. M., \& Turner, R. H. (2008). Fundamentals of Thermal-Fluid Sciences. McGraw-Hill Higher Education.

Churchil, S. W., \& Ozoe, H. (1973). Correlations for laminar forced convection with uniform heating in flow over a plate and in developing and fully developed flow in a tube. Journal of Heat Transfer-Transactions of the Asme, 95, 78-84. http://dx.doi.org/10.1115/1.3450009

Churchill, S. W., \& Chu, H. H. S. (1975). Correlating equations for laminar and turbulent free convection from a vertical plate. International Journal of Heat and Mass Transfer, 18, 1323-1329. http://dx.doi.org/10.1016/0017-9310(75)90243-4 
Date, A. (2010). Cooling of solar cells by chimney-induced natural draft of air. 48th AuSES Conference SOLAR 2010. Canberra.

Haaf, W., Gmayr, K. F., \& Schlaich, J. (1983). Solar chimneys Part I: principle and construction of the pilot plant in Manzanares. International Journal of Solar Energy, 3-20. http://dx.doi.org/10.1080/01425918308909911

Kermani, E., Dessiatoun, S., Shooshtari, A., \& Ohadi, M. M. (2009). Experimental investigation of heat transfer performance of a manifold microchannel heat sink for cooling of concentrated solar cells. In: Electronic Components and Technology Conference, 2009. ECTC 2009. 59th. pp. 453-459.

King, D. L., Kratochvil, J. A., \& Boyson, W. E. (1997). Temperature coefficients for PV modules and arrays: measurement methods, difficulties, and results. In: Photovoltaic Specialists Conference, 1997. Conference Record of the Twenty-Sixth IEEE. pp. 1183-1186.

Krauter, S., Araújo, R. G., Schroer, S., Hanitsch, R., Salhi, M. J., Triebel, C., \& Lemoine, R. (1999). Combined photovoltaic and solar thermal systems for facade integration and building insulation. Solar Energy, 67, 239-248. http://dx.doi.org/10.1016/S0038-092X(00)00071-2

Mayhew, Y. R., \& Rogers, G. F. C. (1995). Thermodynamic and Transport Properties of Fluids. Oxford: Blackwell Publishing Ltd.

Moshfegh, B., \& Sandberg, M. (1996). Investigation of fluid flow and heat transfer in a vertical channel heated from one side by PV elements, part I - Numerical Study. Renewable Energy, 8, 248-253. http://dx.doi.org/10.1016/0960-1481(96)88856-2

Moshfegh, B., \& Sandberg, M. (1998). Flow and heat transfer in the air gap behind photovoltaic panels. Renewable and Sustainable Energy Reviews, 2, 287-301. http://dx.doi.org/10.1016/S1364-0321(98)00005-7

Royne, A., Dey, C. J., \& Mills, D. R. (2005). Cooling of photovoltaic cells under concentrated illumination: a critical review. Solar Energy Materials and Solar Cells, 86, 451-483. http://dx.doi.org/10.1016/j.solmat.2004.09.003

Sandberg, M., \& Moshfegh, B. (1996). Investigation of fluid flow and heat transfer in a vertical channel heated from one side by PV elements, part II - Experimental study. Renewable Energy, 8, 254-258. http://dx.doi.org/10.1016/0960-1481(96)88857-4

Sandberg, M., \& Moshfegh, B. (2002). Buoyancy-induced air flow in photovoltaic facades: Effect of geometry of the air gap and location of solar cell modules. Building and Environment, 37, 211-218. http://dx.doi.org/10.1016/S0360-1323(01)00025-7

Schlaich, J. (1995). The Solar Chimney - electricity from sun. Berlin: Edition Axel Menges.

Tonui, J. K., \& Tripanagnostopoulos, Y. (2008). Performance improvement of PV/T solar collectors with natural air flow operation. Solar Energy, 82, 1-12. http://dx.doi.org/10.1016/j.solener.2007.06.004

Whitaker, S. (1972). Forced convection heat transfer correlations for flow in pipes, past flat plates, single cylinders, single spheres, and for flow in packed beds and tube bundles. AIChE Journal, 18, 361-371. http://dx.doi.org/10.1002/aic.690180219 